\title{
Indicators of Violence Levels: Questionnaires and Predictive Mathematical Model
}

\author{
E. Leal-Enríquez $\mathbb{D}^{1}$ and A. R. Gutiérrez-Antúnez ${ }^{2}$ \\ ${ }^{1}$ Insituto Politécnico Nacional. Av. Luis Enrique Erro S/N, Unidad Profesional Adolfo López Mateos, Zacatenco, \\ Alcaldía Gustavo A. Madero, C.P. 07738, Ciudad de México, Mexico \\ ${ }^{2}$ Universidad del Valle de México, Calz. de Tlalpan 3016/3058, Coapa, Ex-Hacienda Coapa, Ciudad de México, Mexico
}

Correspondence should be addressed to E. Leal-Enríquez; fiserik@yahoo.com.mx

Received 5 September 2019; Revised 7 February 2020; Accepted 15 February 2020; Published 17 March 2020

Academic Editor: Michele Cali

Copyright (C) 2020 E. Leal-Enríquez and A. R. Gutiérrez-Antúnez. This is an open access article distributed under the Creative Commons Attribution License, which permits unrestricted use, distribution, and reproduction in any medium, provided the original work is properly cited.

\begin{abstract}
In this paper, we present, in detail, how a mathematical model that simulates the probable scenarios of intimate partner violence is linked to the application of any questionnaire of domestic violence already in use. This questionnaire assigns a weight of severity to each proposed inquiry for the types of psychological, physical, and sexual violence. We show a numerical procedure that must be performed to obtain the probable scenarios of violence in which the victim is involved, taking as key factor the loss of control of the perpetrator. With the numerical data obtained from the application of the mathematical model, the probable levels of violence that the victim could experience month to month for two cycles of violence are plotted, as well as the behaviors of the probable states of loss of control that the perpetrator would have during the next twelve months. Based on the results obtained, we generated a help table of indicators that could be used by victim assistance centers and/or health experts for decision-making schemes.
\end{abstract}

\section{Introduction}

Violence (the intentional use of physical force or power, threatened or factual, against oneself, another person, or a community or against a group, that either results in or has a high likelihood of resulting in psychological harm, death, injury, deprivation, or maldevelopment [1]) is a serious public health problem that affects all societies around the world [2]. In particular, a type of violence that leads the agendas of the main international organizations and human rights groups (the United Nations define violence against women as "any act of gender-based violence that results in, or is likely to result in, physical, sexual, or psychological harm or suffering to women, including threats of such acts, coercion, or arbitrary deprivation of liberty, whether occurring in public or in private life [3]) is the violence against the woman $[1,4,5]$. This type of violence does not distinguish social classes, race, age, or religious beliefs [6]. Statistical studies indicate that approximately $75 \%$ of the time, it is the man who is identified as being the perpetrator of the cases of violence and the woman his victim. Once that violence has started, there are programs for its monitoring and support, which last on average approximately from one to two years [4].

Once the woman has been detected as a victim of Intimate Partner Violence (IPV) by a governmental or private institution (health worker), assistance to the victim is provided, through its monitoring and the application of risk assessment programs, where such programs last on average from one to two years (several studies have measured the average level of violence in monthly intervals during an observational period of one year [4]) [4, 7]. It is very important that the health worker provides good care to the victims because only some of them seek help, emotional support, advice, and information on how to solve their conflicts with their partners (the percentage of perpetrators and victims seeking help varies in age, race, and social class, among others (for example, the percentage of adolescents seeking help is around $21 \%$ [8]). For example, the percentage of teenagers who do not seek help is around 79\% [8]. With 
this premise, it is important to have quantitative and qualitative tools and contribute to the decision-making process that could help the victim to solve her problems of intimate partner violence (a cycle of domestic violence is basically composed of occurrence of violent incidents (physical/sexual/emotional), stage of accumulation of tension (violent explosions), and honeymoon phase [9]).

Currently, predictive tools are being developed to detect if a woman is a victim of domestic violence, as well as mathematical models to obtain the probable levels of violence, that could be experienced during the next twelve months [10-12].

These predictive tools could have benefits for victims by showing them their likely scenarios of levels of violence that they might experience if they do not seek help and/or undergo some treatment to solve some of their problems $[8,12]$. In particular, the mathematical model proposed by Leal-Enrquez [12] calculates the probable levels of IPV that could arise in a period of twelve months, taking as input the first diagnosis of the level of violence with which the victim arrives at the center of attention (in order to obtain the initial level of violence to the victim (statistics), initial of the victim, questionnaires are applied, which take into account the frequency of violent acts $[5,13])$.

However, this mathematical model does not show, in a simple way, how a social worker (or someone interested in simulating their likely levels of violence) could use it from of a questionnaire (the estimation of the initial level of violence can be quantified through the application of questionnaires, where each query is assigned a numerical weight of severity [5]). The difficulty in the works over predictive mathematical models that obtain indicators of violence is that they do not show its usefulness with clinical applications because the authors do not show how to use violence risk questionnaires combined with the mathematical model in a simple way or with some examples.

Therefore, in this work, a complete example of how to use the model proposed by Leal-Enrquez [12] is developed, taking into account the questionnaire applied to the victim, when she arrives at the center of attention.

The premises taken by the model are that the perpetrator is accumulating every month his probability of losing control and that such loss of control manifests itself as domestic violence towards his partner in cycles of abuse $[12,14,15]$, based on a model, in which the perpetrator presents psychological limitations to control his violent impulses [16].

The key variables used by the mathematical model to simulate the probable scenarios of violence that the victim can suffer are the loss of control of the perpetrator (a factor that contributes to reducing the levels of violence is the treatment of the loss of control (some studies report that levels of violence are reduced up to $53 \%$, when the perpetrators register and remain in the aid programs along a year [16])), the weights assigned to each question of the applied questionnaire, as well as the frequencies of the violent acts (to assign the weights and frequencies to each question, statistical studies and meetings with experts in the field of
IPV are carried out, an example of this can be reviewed in $[5,13])$.

Domestic violence treatments are socially justifiable because of the opportunity given to the perpetrators to control their violent behavior [16, 17]. It should be mentioned that the aid programs (regularly quantify their effectiveness in a statistical way in monthly periods [17]) share the objective of reducing the levels of domestic violence by providing assistance to the victims.

Therefore, with the aim of helping social workers and victims, in this article, we present the use and probable applications of the mathematical model proposed [12], which simulates the probable scenarios of levels of violence that might experience one victim of domestic violence throughout one year.

\section{Questionnaire}

In this section, we take one questionnaire (methodological proposal to measure intimate partner violence in women [5]) that measures the dimensions of the psychological, sexual, physical, and severe physical violence, in order to link the mathematical model proposed by Leal-Enrquez [12], with a questionnaire that estimates, in a quantitative form, the initial level of domestic violence of the victim (the social worker and/or center of attention can use their own questionnaires and/or protocols to obtain the initial condition of violence of the victim (see, for example, $[5,13])$ ).

In Table 1, the questionnaire to be used, which incorporates basically 18 items selected from two instruments (Index of Spouse Abuse (ISA) and the Severity of Violence Against Women Scale (SVAWS) $[18,19]$ ) is shown, which has proven useful for the quantification of male violence towards women in a relationship. In this questionnaire, it is observed the variables $\omega_{n}$ (weight (score) assigned to the violent actions of each of the items (the method for assigning these weights is by expert judgment $[5,13])$ ) and the frequency of violent actions were experienced in recent months $f_{n}$, where the values assigned to these frequencies are $0=$ never, $1=$ sometimes, $2=$ several times, and $3=$ many times. In this questionnaire, we have the following factors: I = psychological violence, $\mathrm{II}$ = physical violence, $\mathrm{III}=$ severe physical violence, and IV = sexual violence.

To assign to each item the factor that corresponds to it, a numerical value between $\left[\begin{array}{ll}0 & 1\end{array}\right]$ is used together with a factorial analysis (for more details of this analysis see [5]).

Later, a frequency is assigned $f_{n}$, as well as the weight $\omega_{n}$, to each item; therefore, the level of violence $\Omega_{n}$ is calculated by the following equation $[5,12]$ :

$$
\Omega_{n}(0)=\omega_{n}(0) \times f_{n}(0),
$$

where $f_{n}(0)=0,1,2,3$ and $\omega_{n}(0)$ take the values from Table 1. For example, when a woman, victim of violence, is reported to have been burned with a cigar $(n=11)$ or another substance several times $\left(f_{n}=2\right.$ and $\left.\omega_{n}=6\right)$, we have [5]

$$
\Omega_{11}(0)=\omega_{11}(0) \times f_{11}(0)=6 \times 2=12 .
$$


TABLE 1: Initial condition of violence $\Omega(0)$ by frequency $f_{n}$, weight $\omega_{n}$, and dimension.

\begin{tabular}{|c|c|c|c|c|c|c|c|}
\hline \multirow[b]{2}{*}{$n$} & \multirow[b]{2}{*}{ Question } & \multirow[b]{2}{*}{ Factor } & \multicolumn{2}{|c|}{ Weight } & \multicolumn{2}{|c|}{$\Omega_{n}(0)$} & \multirow[b]{2}{*}{$\begin{array}{c}f_{n} \\
3\end{array}$} \\
\hline & & & $\omega_{n}$ & $\begin{array}{c}f_{n} \\
0\end{array}$ & $\begin{array}{c}f_{n} \\
1\end{array}$ & $\begin{array}{c}f_{n} \\
2\end{array}$ & \\
\hline 1 & Has he told you that you are unattractive or ugly? & I & 4.5 & 0 & 4.5 & 9 & 13.5 \\
\hline 2 & Has he become jealous or suspected your friends? & I & 4 & 0 & 4 & 8 & 12 \\
\hline 3 & Has he rejected you? & I & 5 & 0 & 5 & 10 & 15 \\
\hline 4 & Has he insulted you? & I & 4 & 0 & 4 & 8 & 12 \\
\hline \multirow[t]{2}{*}{5} & Has he disparaged you in front of other people? & I & 5.5 & 0 & 5.5 & 11 & 16.5 \\
\hline & Indicator of psychological violence & $\Omega_{\mathrm{I}}(\mathbf{0})$ & & $\mathbf{0}$ & 23 & 46 & 69 \\
\hline 6 & Has he kicked you? & II & 8 & 0 & 8 & 16 & 24 \\
\hline 7 & Has he pushed you intentionally? & II & 5 & 0 & 5 & 10 & 15 \\
\hline 8 & Has he punched you or slapped on your face? & II & 7 & 0 & 7 & 14 & 21 \\
\hline 9 & Has he twisted your arm? & II & 6.5 & 0 & 6.5 & 13 & 19.5 \\
\hline \multirow[t]{2}{*}{10} & Has he jerked you? & II & 5 & 0 & 5 & 10 & 15 \\
\hline & Indicator of physical violence & $\Omega_{\mathrm{II}}(\mathbf{0})$ & & $\mathbf{0}$ & 31.5 & 63 & 94.5 \\
\hline 11 & Has he burned you with a cigar or other substances? & III & 6 & 0 & 6 & 12 & 18 \\
\hline 12 & Has he threatened you with a gun or rifle? & III & 6.5 & 0 & 6.5 & 13 & 19.5 \\
\hline 13 & Has he shot you with a gun or rifle? & III & 9.5 & 0 & 9.5 & 19 & 28.5 \\
\hline 14 & Has he threatened you with a knife? & III & 7 & 0 & 7 & 14 & 21 \\
\hline \multirow[t]{2}{*}{15} & Has he tried to drown you or suffocate you? & III & 9.5 & 0 & 9.5 & 19 & 28.5 \\
\hline & Indicator of severe physical violence & $\Omega_{\mathrm{III}}(\mathbf{0})$ & & $\mathbf{0}$ & 38.5 & 77 & 115.5 \\
\hline 16 & Has he demanded you to have sex? & IV & 6 & 0 & 6 & 12 & 18 \\
\hline 17 & Has he used physical force to have sex? & IV & 9 & 0 & 9 & 18 & 27 \\
\hline \multirow[t]{3}{*}{18} & $\begin{array}{l}\text { Has he threatened you with leaving you for other women if you } \\
\text { do not agree to have sex? }\end{array}$ & IV & 4 & 0 & 4 & 8 & 12 \\
\hline & Indicator of sexual violence & $\Omega_{\mathrm{IV}}(\mathbf{0})$ & & $\mathbf{0}$ & 19 & 38 & 57 \\
\hline & Initial condition of global violence & $\boldsymbol{\Omega}(\mathbf{0})$ & & $\mathbf{0}$ & 112 & 224 & 336 \\
\hline
\end{tabular}

$\mathrm{I}$ = psychological violence; $\mathrm{II}$ = physical violence; $\mathrm{III}$ = severe physical violence; $\mathrm{IV}$ = sexual violence.

Hence, the level of initial violence of the victim $\Omega(0)$, taking into account each one of the factors I, II, III, and IV (where each of the questions has already been related to its dimension (to obtain the dimension of each question, a factorial analysis is usually carried out to identify the grouping of the variables that best explain the dimensions, thus obtaining their factors for each type of violence [5])), is obtained by the following equation $[5,12]$ :

$$
\Omega(0)=\sum_{n=1} \omega_{n}(0) f_{n}(0) .
$$

Equation (3) can be separated by each of the four factors that make up the applied questionnaire; for example, for the questionnaire shown in Table 1, we obtain

$$
\begin{aligned}
\Omega(0)= & \sum_{n=1}^{5} \omega_{n}(0) f_{n}(0)+\sum_{n=6}^{10} \omega_{n}(0) f_{n}(0)+\sum_{n=11}^{15} \omega_{n}(0) f_{n}(0) \\
& +\sum_{n=16}^{18} \omega_{n}(0) f_{n}(0) \\
= & \Omega_{\mathrm{I}}(0)+\Omega_{\mathrm{II}}(0)+\Omega_{\mathrm{III}}(0)+\Omega_{\mathrm{IV}}(0) .
\end{aligned}
$$

The indicator of violence given in (3) is global and indicates the initial condition of violence with which the victim reaches the center of attention (note that this indicator considers the psychological, physical, severe physical, and sexual dimensions [5]) (or the health worker). In Table 1, the calculation of the initial global condition is shown (see (3)) and for dimensions (see (4)) for homogeneous frequencies [5].

In Table 1, the calculation of the initial global condition (see (3)) and by dimensions (see (4)) for homogeneous frequencies is shown [5].

2.1. Categorization. To verbally categorize the initial condition of IPV in [5], the following is proposed (the way to categorize the initial condition of violence is based on the minimum, maximum, and average value of the data obtained for each domestic violence factor that was considered; for more details, see [5]) (see Table 1):

(i) Factor I: the case is considered as "no case of psychological violence," and the values of $\Omega_{\mathrm{I}}(0)$ are between 0 and 5 points. If the indicator is in the range of values from 5.1 to 18.2, there is "a case of psychological violence" and "case of severe psychological violence" if $\Omega_{\mathrm{I}}(0)$ belongs to the range of values between 18.3 and 69 .

(ii) Factor II: the cases are considered as "no cases," and the values are between 0 and 2.4. If $\Omega_{\text {II }}(0)$ takes values from 2.4 to 12 , it is taken as "a case of physical violence." Finally, if the indicator takes values between 12.1 and 94.5 , it is considered "a case of high physical violence."

(iii) Factor III: the cases are considered as "no cases" if $\Omega_{\text {III }}(0)=0$ and as "case of severe physical violence" if the indicator is greater than 0 ; that is, there is 
severe physical violence if the victim lives some of the acts considered in dimension III (see Table 1).

(iv) Factor IV: the cases are considered as "no cases of sexual violence" if the indicator takes values between 0 and 1 . If $\Omega_{\mathrm{IV}}(0)$ is between 1.1 and 6 , it is considered "as a nonsevere case of sexual violence;" finally, if the indicator is in the range of values between 6.1 and 84 , it is "a severe case."

\section{Model: $\boldsymbol{\Omega}(k)$}

Once that the violence questionnaire and the categorization are applied, it is possible to simulate the probable levels of violence that the victim could experience over the next twelve months; starting from their initial condition of global violence or by dimensions, $\Omega(0)$ (see Table 1 and (1)-(4)), to achieve this, we use the model proposed by Leal-Enrquez [12], which is given by

$$
\Omega(k)=\Omega(0) \prod_{j=1}^{k} \alpha_{j},
$$

where

$$
\Omega(0)=\sum_{n=1} \omega_{n}(0) f_{n}(0)
$$

Note that, the index $k$ takes values from of 1 , i.e., $k>j$ (next months from $j$ ); therefore,

(i) If $j>k$,

$$
\prod_{j}^{k} \alpha_{j}=1 .
$$

The indicator $\Omega(0)$ is the initial condition of IPV (see (1) and (4)). The factors $\omega(0)$ and $f(0)$ are the assigned weight and the frequency of each one of the $n$ items of the questionnaire applied to the victim, respectively (for details of the methods employed to obtain the values presented in Table 1, see [5]). The proportionality factor $\alpha_{j}$ takes into account the accumulation of violence due to the probable loss of control of the perpetrator during the next $j$ months, which is given by

$$
\alpha_{j}=\sum_{i=1}^{j} \beta_{i}
$$

with

$$
\begin{gathered}
\beta_{i}=\xi_{i} \times \sigma_{-}(i) \\
{\left[\begin{array}{ll}
\sigma_{+}(i) & \sigma_{-}(i)
\end{array}\right]=\left[\begin{array}{ll}
\sigma_{+}(0) & \sigma_{-}(0)
\end{array}\right]\left[\begin{array}{cc}
(1-\lambda) & \lambda \\
\mu & (1-\mu)
\end{array}\right]^{i}}
\end{gathered}
$$

The factor $\beta_{i}$ (for $i=1,2, \ldots, j$ ) is proportional to the probable states of loss of control of the perpetrator $\sigma_{-}(i)$; for one month, $i$ is specified. $\xi_{i} \in\left[\begin{array}{ll}0 & 1\end{array}\right]$ is the proportion that takes into account the percentage of loss of control of the perpetrator that can be reflected as injuries or violent acts towards his partner (see Table 1, dimensions I, II, III, and IV). The elements of the vector $\left[\sigma_{+}(i) \sigma_{-}(i)\right]$ are the probabilities that the perpetrator is in a state of self-control or loss of self, respectively. The components $(1-\lambda)$ and $(1-$ $\mu) \in\left[\begin{array}{ll}0 & 1\end{array}\right]$ are parameters associated with the prevalence of the perpetrator being in a state of self-control or loss of self [12]. The vector $\left[\sigma_{+}(0) \sigma_{-}(0)\right] \in\left[\begin{array}{ll}0 & 1\end{array}\right]$ is the probabilities that the perpetrator is in a state of self-control or loss thereof, both values assigned at the beginning of the risk assessment of the victim (to model the perpetrator's self-control and loss states, a finite Markov chain is used; for more details, see [12]).

To show the application of equations (5)-(10), we will use the data of the indicator $\Omega_{\mathrm{III}}(0)$ for the case of severe physical violence (the value of $(1-\mu)$ was approximated by the prevalence of physical violence reported as $23.4 \%$; study carried to the workers of the IMSS of the state of Morelos, México. The value of the probability of loss of control of the perpetrator is equal to 1 because the woman is already a victim of domestic violence $[12,20])$; for a frequency of "many times," $f_{n}=3$ (see Table 1), and these data are complemented with those proposed in [12]; therefore, we have $\sigma_{-}(0)=1, \quad \sigma_{+}(0)=0, \quad 1-\mu=0.234, \quad \mu=0.7660$, $\Omega_{\mathrm{III}}(0)=115.5$, and $\lambda$ random.

Because a victim comes to the attention centers when violent acts are already aroused, we take the following values for the proportion of loss of control of the perpetrator $\xi_{i}$ that can be reflected as injuries or violent acts during a period of twelve months (the distribution of data for $\xi_{i}$ is established taking into account a cycle of violence between a perpetrator and a victim of IPV $[9,12])[12]$ :

$$
\begin{array}{rllllll}
\xi_{i}=\left[\begin{array}{llllll}
0.3135 & 0.0763 & 0.2003 & 0.6556 & 0.9272 & 0.840 \\
0.6358 & 0.3424 & 0.8803 & 0.0450 & 0.0619 & 0.0794
\end{array}\right] .
\end{array}
$$

Substituting these values in (10), taking a probability of control prevalence (random) of $\lambda=0.3$ for $i=1,2$ and then its results in (9), we obtain the factor $\alpha_{j}$ (see (8)) for $j=1$ until $k=12$. Finally, with the values obtained from (9) and the initial condition of violence $\Omega_{I I I}(0)$ (see Table 1 ), we can get the indicator of IPV $\Omega(k)$ (see (5)) for $k=1,2$, until 12 . In Table 2, the results of this procedure are shown.

3.1. Simulations. Performing simulations from mathematical models is important because they can be used as exploration tools to predict consequences based on certain hypotheses [21]. In particular, the scenario that must be assumed in order to use the model of domestic violence $\Omega(k)$ (see equations $(5)-(10))$ is that the perpetrator has a violent nature (the probability that a man is violent can be obtained through clinical studies conducted by experts, an example of this can be reviewed in [22]); we will also assume that, on average, the perpetrator, month after month, changes his state of self-control where his victim is a submissive woman and without character. This implies that, for $k=0$, the value of $\sigma_{-}(0)=1[10,12,23,24]$. 
TABLE 2: Indicators of violence level scenarios.

\begin{tabular}{lcccc}
\hline Month & $\sigma_{-}^{1}$ & $\beta^{1}$ & $\alpha^{1}$ & $\Omega_{\text {III }}^{1}$ \\
\hline 1 & 0.2340 & 0.2340 & 0.2340 & 27.027 \\
2 & 0.8208 & 0.4925 & 0.7265 & 19.634 \\
3 & 0.3713 & 0.1485 & 0.8750 & 17.179 \\
4 & 0.7156 & 0.5009 & 1.3759 & 23.636 \\
5 & 0.4519 & 0.3615 & 1.7374 & 41.065 \\
6 & 0.6539 & 0.2289 & 1.9662 & 80.744 \\
7 & 0.4991 & 0 & 1.9662 & 158.76 \\
8 & 0.6177 & 0.0062 & 1.9724 & 313.14 \\
9 & 0.5269 & 0.0105 & 1.9829 & 620.94 \\
10 & 0.5964 & 0.1193 & 2.1022 & 1305.4 \\
11 & 0.5431 & 0.1629 & 2.2652 & 2956.9 \\
12 & 0.5840 & 0.0584 & 2.3236 & 6870.4 \\
\hline
\end{tabular}

The simulations (in particular, the programming of the mathematical model (5)-(10) was done in MatLab [25]; however, the calculations can be done in software such as Excel) were done taking the values of Section 3 for five probable prevalence of the state of control of the perpetrator (the health worker should assign these values depending on the number of scenarios that you wish to simulate to observe the probable levels of violence that the victim of domestic violence could experience [12] $) \quad(1-\lambda)=\left[\begin{array}{ll}0 & 0.2\end{array}\right.$ $\left.\begin{array}{lll}0.4 & 0.6 & 0.8\end{array}\right]$ assigned to this work in a random manner. Therefore, following the procedure shown in equations (5)-(10), the values of $\Omega_{\mathrm{III}}^{n}(k)$ are obtained where $n=1,2,3$, 4, 5 represents each of the simulated scenarios (the choice of the five probable scenarios was done in a heuristic way, taking into account that the authors want to see the behavior when the perpetrator remains in his self-control state).

3.2. Simulation: Tension-Explosion-Honeymoon. In Figure 1(a), the possible scenarios of the perpetrator's control loss $\sigma_{-}(i)$ (see (10)) are shown. Figure $1(b)$ shows $\xi_{i}$ for a period of one year and divided into three parts derived from the cycle of violence: tension-explosion of violent actshoneymoon [12]. In Figure 1(c), the coefficients $\beta_{i}$ proportion of loss of control of the perpetrator that may manifest as violent acts towards his victim (see (9)) are plotted. In Figure 1(d), the accumulation factor $\alpha_{j}$ is shown for each month (see (8)). In Figures 2(a) and 2(b), the probable values of the indicator of IPV $\Omega_{\mathrm{III}}^{n}(k)$ are plotted, where its probable evolution for three, six, nine, and twelve months can be seen (see histogram (the union of the values in Figures 1 and 2 was done through lines with the purpose of facilitating their follow-up through the months)).

3.3. Simulation: Explosion-Honeymoon-Tension. Finally, a simulation taking the following values of $\xi_{i}$ is developed:

$$
\begin{aligned}
\xi_{i}= & {\left[\begin{array}{lllllll}
1 & 0.6 & 0.4 & 0.7 & 0.8 & 0.35 & 0 \\
& 0.01 & 0.02 & 0.2 & 0.3 & 0.1
\end{array}\right], }
\end{aligned}
$$

which represent that the victim is in the cycle: explosion of violent acts, honeymoon, and tension [12].
In Figure 3, the possible scenarios of loss of control of the perpetrator $\sigma_{-}(i)$ (see (10)) are shown, as well as the factor $\xi_{i}$ for a period of one year derived from the cycle of violence: explosion, honeymoon, and tension [12]. The coefficients $\beta_{i}$ of the proportion of loss of control of the perpetrator that may manifest as violent acts towards his victim (see (9)), and the factor of accumulation $\alpha_{j}$ (see (8)) is plotted.

In Figure 4, the probable values of the indicator of domestic violence $\Omega_{\mathrm{III}}^{n}(k)$ are shown, as well as their histogram, where we can observe the behavior of the indicator for three, six, nine, and twelve months (the distribution of data for $\xi_{i}$ is established taking into account a cycle of violence between a perpetrator and a victim of IPV $[9,12])$.

Note that only the simulations were carried out for two probable cycles of violence. This is due to the fact that the victim goes to the attention centers when she has suffered some kinds of violent incident $[5,16,26]$.

\section{Discussion and Conclusions}

This paper shows the use of a quantitative tool that probably can contribute to risk assessment, as well as helping care centers and victims to break the cycle of violence. This is possible because when the victim comes to the care center, their initial risk of violence can be assessed $\Omega(0)$ (see (3) and (4)), with the help of a questionnaire (specific to the center of attention, see Table 1), where the said questionnaire has assigned weights of severity to each one of the items, as well as the frequency of the violent acts, that the victim reports. Once obtained $\Omega(0)$, the said value can be used to simulate the probable scenarios of violence that the victim could experience at the hands of her perpetrator using the model proposed by [12] for $\Omega(k)$ (see equations (5)-(10)). This model graphs the probable behaviors of the loss of control of the perpetrator (see Figure 1(a)), which can be used by the health expert to show the victim and ask her, which of these scenarios are those that are most attached to the behavior of her perpetrator (or the expert identifies them [23]). With the selection of scenarios, the probable levels of violence $\Omega^{n}(k)$ that could arise over the next twelve months can be obtained (see Figure 2(a) and Table 2); with this information, the expert would have an idea of the probable danger that the victim could experience; see, for example, the graph Figure 4(b) and Table 2, where it is observed that there is a scenario of loss of control of the perpetrator that could culminate in a level of violence $\left(\Omega_{\mathrm{III}}^{1}(12)=6870.4\right)$ value that exceeds the initial condition $\Omega(0)$ with which the victim was evaluated in the initial interview. This could be interpreted as a probable fatality scenario, following the categorization criteria established in Section 2.1. Note that, with the data calculated by the mathematical model, the center of attention could be guided to make a decision of what actions to take to help the victim of IPV. To illustrate in more detail all of the above, Table 2 is presented, where the results for the scenario $n=1$ are shown for values $\xi_{i}$ (see Figure 3 ), assuming that the health expert identifies that the perpetrator probably has this behavior.

From Table 2, it can be seen that violence is really dangerous from the ninth month. That is, if the health expert 


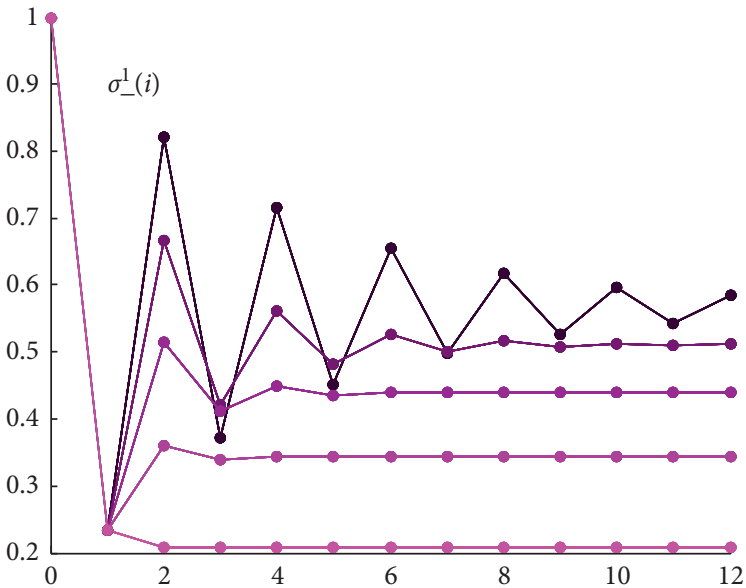

(a)

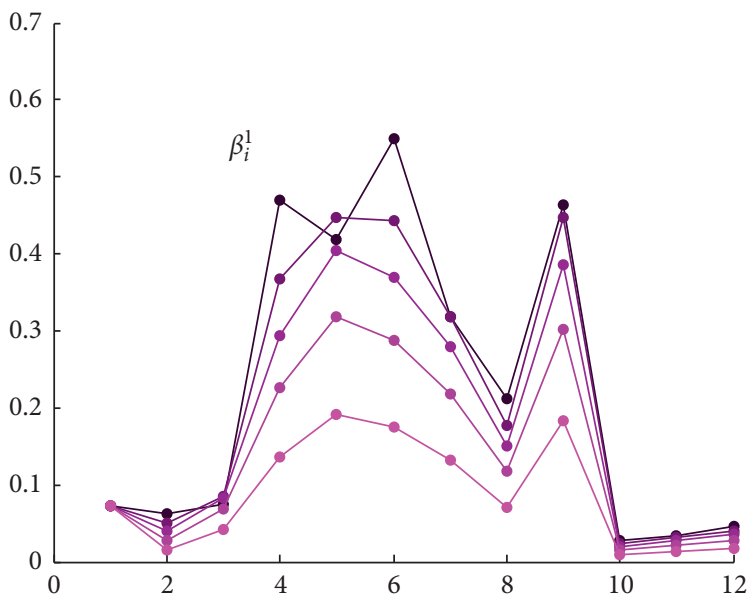

(c)

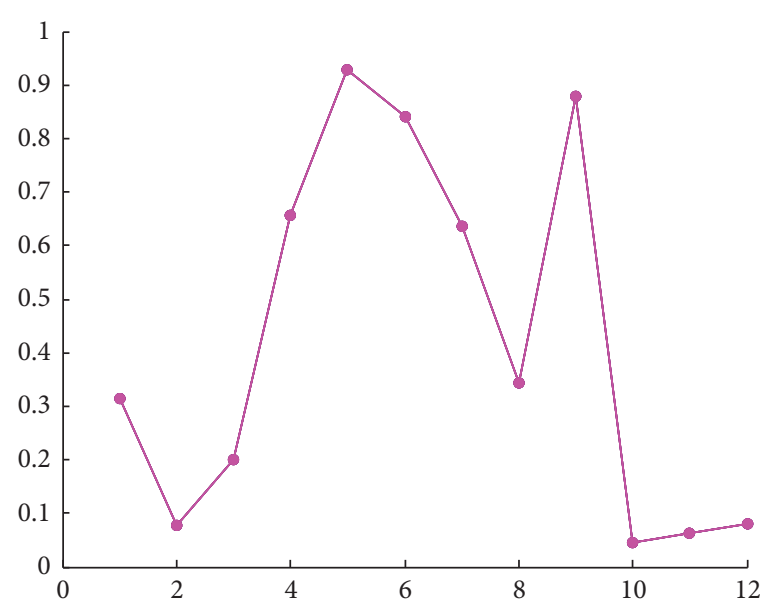

(b)

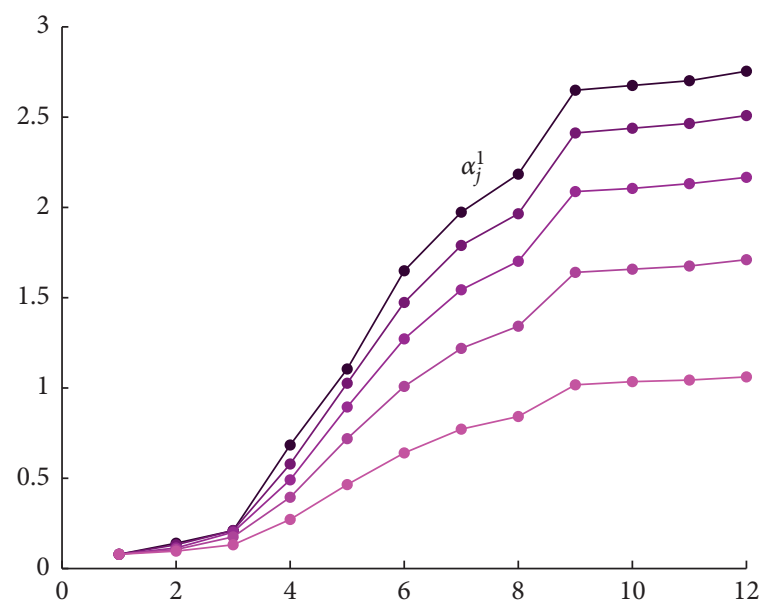

(d)

FIGURE 1: Graphs for a simulation of five scenarios for 12 months. The union of the values by means of lines is only for monitoring purposes. (a) Values of $\sigma_{-}$(i) for a period of twelve months; (b) factor of proportion $\xi_{i}$; (c) $\beta_{i}$ for five probable states of loss of control; (d) accumulation factor $\alpha_{j}$.

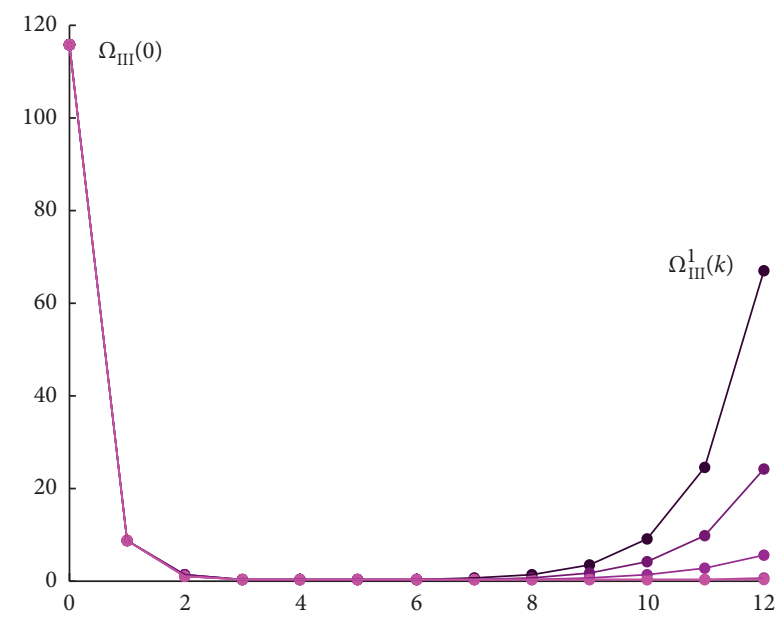

(a)
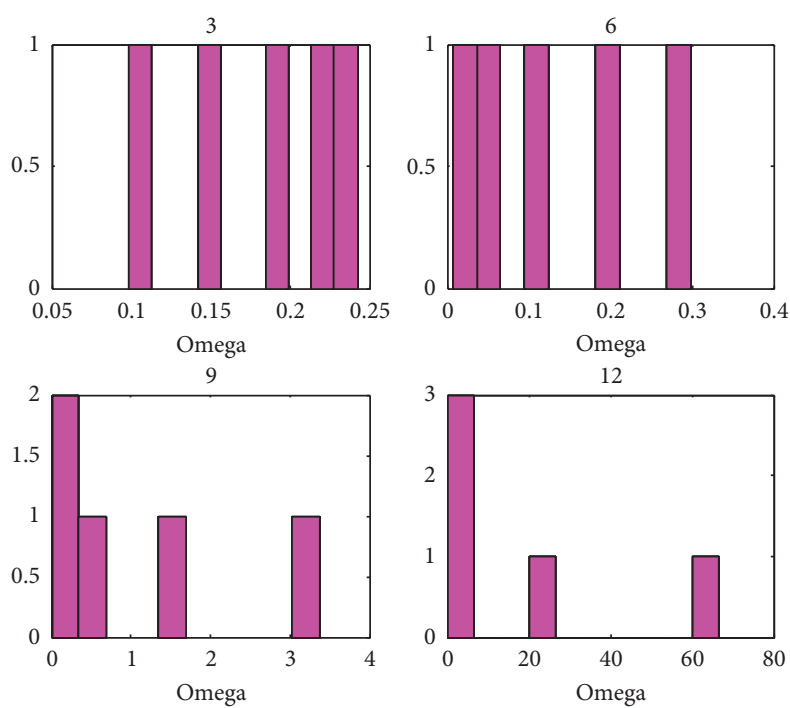

(b)

FIgURE 2: Simulation of five scenarios of violence $\Omega_{\mathrm{III}}(k)$ for a period of three, six, nine, and twelve months for an initial condition of $\Omega_{\mathrm{III}}(0)=115.5$ : (a) $\Omega^{n}(k)$ for twelve months $k=12$; (b) distribution of probable values of $\Omega_{\mathrm{III}}^{n}(k)$. 


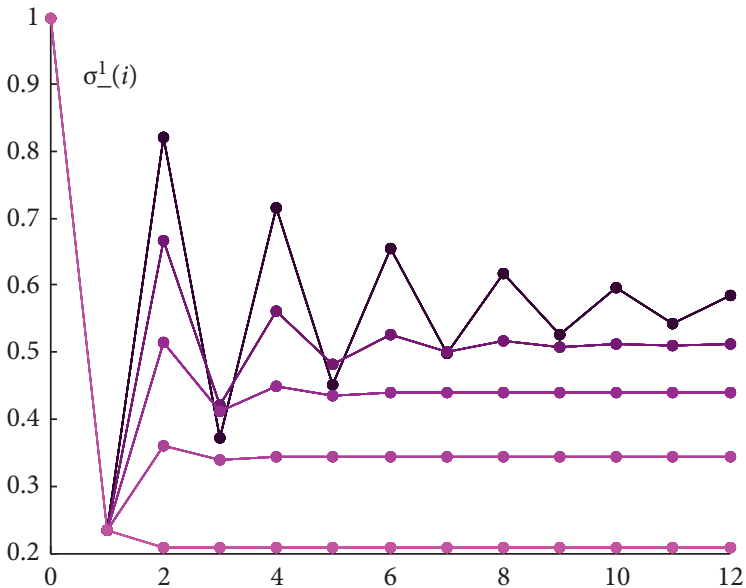

(a)

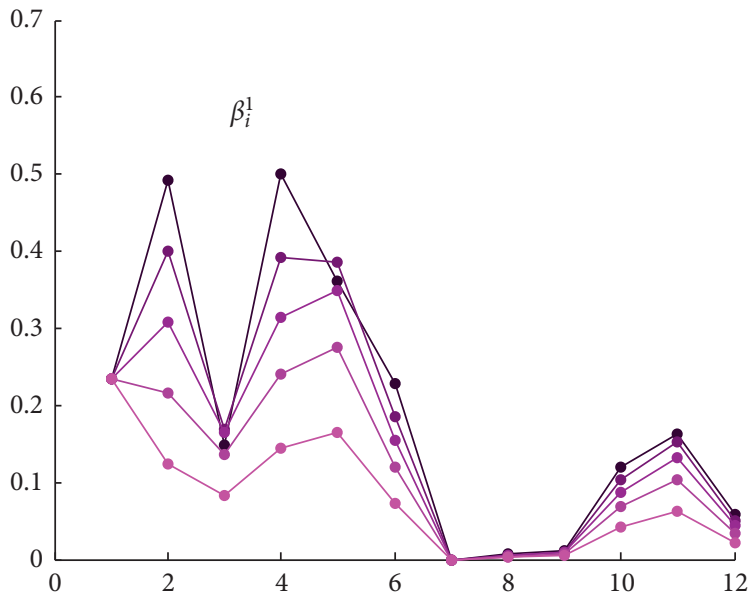

(c)

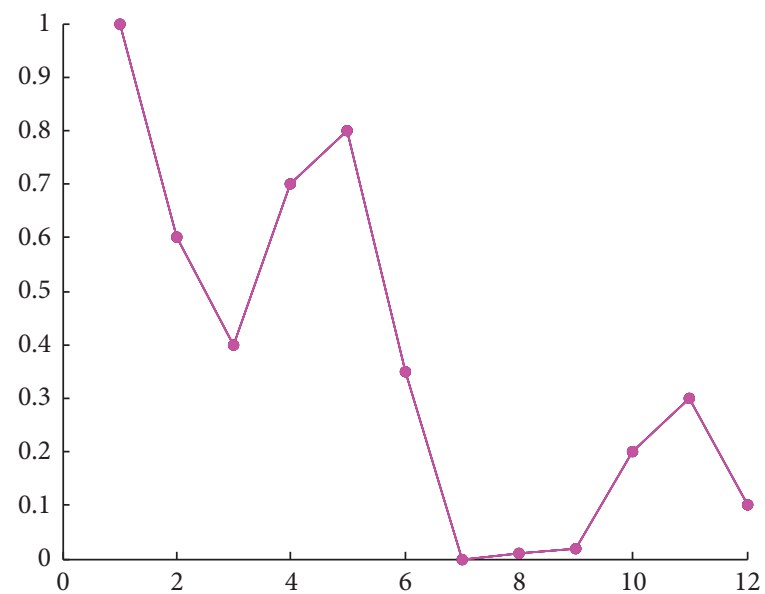

(b)

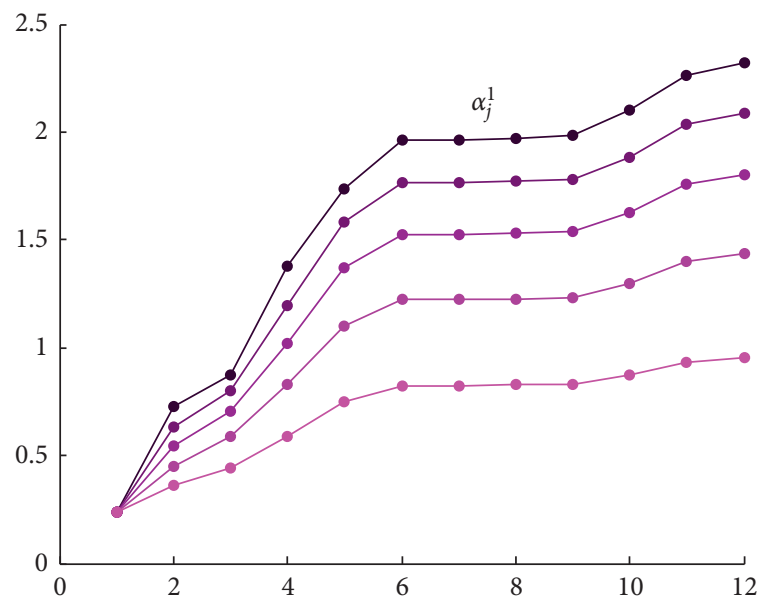

(d)

FIgURE 3: Simulation of five scenarios for 12 months. The union of the values by lines is only for tracking purposes. (a) Values of $\sigma_{-}(i)$ for a period of twelve months; (b) factor of proportion $\xi_{i}$; (c) $\beta_{i}$ for five probable states of loss of control; (d) accumulation factor $\alpha_{j}$.

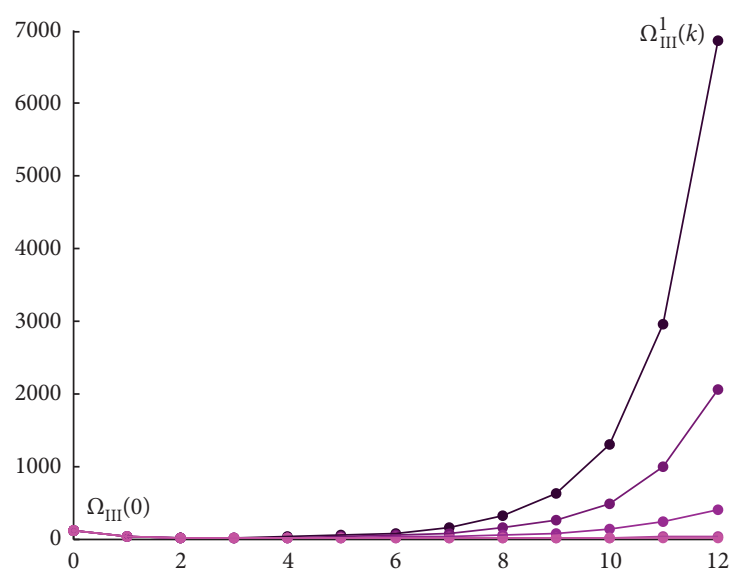

(a)
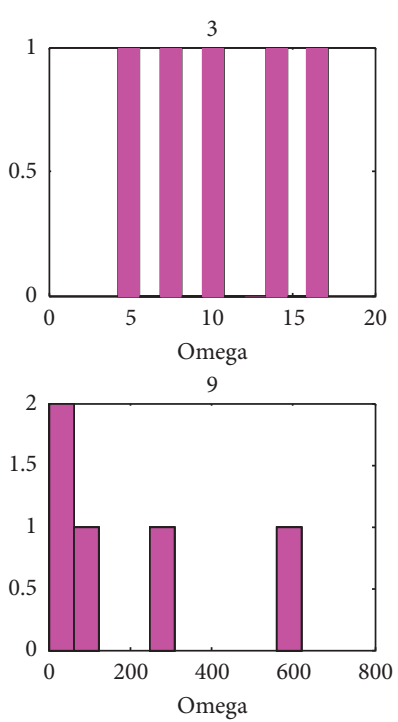

(b)
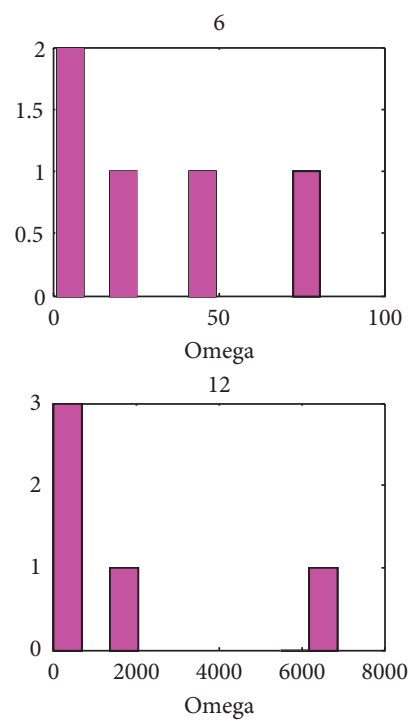

FIGURE 4: Behavior of $\Omega_{\mathrm{III}}(k)$ for a period of three, six, nine, and twelve months for an initial condition of violence $\Omega_{\mathrm{III}}(0)=115.5$ : (a) $\Omega^{n}(k)$ for twelve months $k=12$; (b) distribution of probable values of $\Omega_{\mathrm{III}}^{n}(k)$ vs count. 


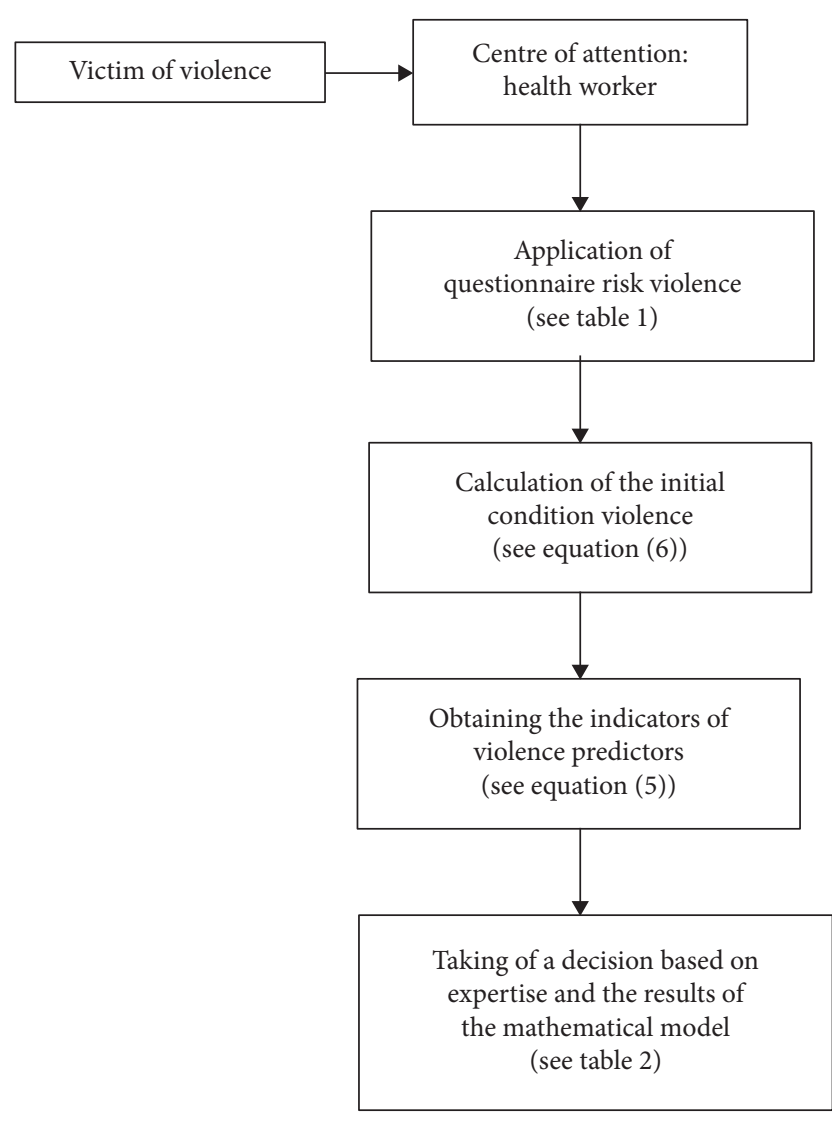

FIGURE 5: Flow diagram to help the health workers in the prediction of the levels of violence.

detects this behavior of loss of control of the perpetrator, they must provide help to the victim for the first six months so as to decrease the levels of violence.

The model (see equations (5)-(10)) is very general because it does not explicitly take into account some specific factors that alter the state of loss of control of the perpetrator, such as alcoholism and drug addiction (to mention a few factors), as well as that it is limited to a model where the victim is completely submissive. In addition, the model takes the premise that the perpetrator has a cumulative process in his loss of control that manifests itself in injuries and/or violent acts towards his partner. However, this model can serve as an aid for the care centers (and above all for the victim) because their current risk can be observed and measured as well as their probable scenarios of violence that could be experienced in the coming months, in the case that the victim is not given adequate help with the purpose of breaking her cycle of violence.

After all of the simulations, it is observed that most of the scenarios do not end in a situation of fatality towards the victim (this conclusion does not intend to pose a generalization) (see Figures 2 and 4 as well as Table 2). In Figure 5, we show a summary of the flow diagram to follow by the use of the mathematical model linked with a questionnaire of risk violence.

As a comment, we hope that this work will be useful for care centers and researchers with the aim of contributing to the study and knowledge of the (complex) phenomenon of violence, which affects all the societies of the world.

\section{Future Work}

Due to the fact that the proposed model (see (5)-(10)) does not consider external aid, we intend to develop social controllers with the aim of reducing the perpetrators loss of control in a percentage, which would likely result in that violence indicator $\Omega(k)$ being reduced. Likewise, we will perform clinical validations (conducted by experts) of the level of violence that presents a victim of IPV in order to compare it with the probable scenarios of violence generated from our proposed model and thus being able to contribute to helping victims to prevent future IPV-related injuries or other types of violence. With this experimental study, we intend to conduct data mining for the validation of a mathematical model and we will have demonstration clinics of the utility of this mathematical model to show how it helps the victims of IPV.

\section{Data Availability}

The data used to support the findings of this study are included within the supplementary information files.

\section{Conflicts of Interest}

The authors declare that they have no conflicts of interest.

\section{References}

[1] World Health Organization (WHO), http://www.who.int/en/.

[2] M. Híjar-medina, M. V. López-lópez, and J. Blanco-muñoz, "La violencia y sus repercusiones en la salud: reflexiones teóricas y magnitud del problema en México," Salud Pública de México, vol. 39, no. 6, pp. 565-572, 1997.

[3] UN Women, 2015, http://www.unwomen.org/en.

[4] T. Fenlason, "Change in intimate partner violence: the domestic couple's perspective on perpetrator change," Doctoral dissertation, Antioch University, Culver City, CA, USA, 2009.

[5] R. Valdez-Santiago, M. C. Híjar-Medina, V. N. Salgado de Snyder, L. Rivera-Rivera, L. Avila-Burgos, and R. Rojas, "Escala de violencia e índice de severidad: una propuesta metodológica para medir la violencia de pareja en mujeres mexicanas," Salud Pública de México, vol. 48, pp. s221-s231, 2006.

[6] D. V. A. Women, Putting Women First, World Health Organization, Geneva, Switzerland, 2001.

[7] SSA, Norma Oficial Mexicana NOM-190-SSA-1999, Prestación de servicios de salud. Criterios Para la Atención de la Violencia Familiar, INSP/SSA, Ciudad de México, Mexico, 1999, http://www.salud.gob.mx/unidades/cdi/nom/190ssa19. html.

[8] O. S. Ashley and V. A. Foshee, "Adolescent help-seeking for dating violence: prevalence, sociodemographic correlates, and sources of help," Journal of Adolescent Health, vol. 36, no. 1, pp. 25-31, 2005.

[9] J. Gunter, "Intimate partner violence," Obstetrics and Gynecology Clinics of North America, vol. 34, no. 3, pp. 367-388, 2007. 
[10] R. Bhargava, T. L. Temkin, B. H. Fireman et al., "A predictive model to help identify intimate partner violence based on diagnoses and phone calls," American Journal of Preventive Medicine, vol. 41, no. 2, pp. 129-135, 2011.

[11] L. R. Halpern and T. B. Dodson, "A predictive model to identify women with injuries related to intimate partner violence," The Journal of the American Dental Association, vol. 137, no. 5, pp. 604-609, 2006.

[12] E. Leal-Enríquez, "Mathematical modeling of intimate partner violence: simulations of loss of control scenarios," Journal of Computational and Applied Mathematics, vol. 330, pp. 1052-1062, 2018.

[13] Z. Sánchez, F. J. I. A. Ovalle, R. Ivette, I. C. Meneses, J. Artemio III, and C. Ambriz, Estudio sobre la violencia de género: la otra cara de la Universidad Autónoma Chapingo/ Francisco José Zamudio Sánchez, Roxana Ivette Arana Ovalle, José Artemio Cadena Meneses, Alejandro Corona Ambriz, Texcoco, Mexico, 2010, http://demyc.chapingo.mx/apps/ pubs/web/index.php?pid=2.

[14] E. J. Finkel, C. N. DeWall, E. B. Slotter, M. Oaten, and V. A. Foshee, "Self-regulatory failure and intimate partner violence perpetration," Journal of Personality and Social Psychology, vol. 97, no. 3, pp. 483-499, 2009.

[15] J. K. Wesely, "Considering the context of women's violence: gender, lived experiences, and cumulative victimization," Feminist Criminology, vol. 1, no. 4, pp. 303-328, 2006.

[16] E. Echeburúa, B. Sarasua, I. Zubizarreta, and P. D. Corral, "Evaluación de la eficacia de un tratamiento cognitivo-conductual para hombres violentos contra la pareja en un marco comunitario: una experiencia de 10 a os (1997-2007)," International Journal of Clinical and Health Psychology, vol. 9, no. 2, 2009.

[17] C. I. Eckhardt, C. M. Murphy, D. J. Whitaker, J. Sprunger, R. Dykstra, and K. Woodard, "The effectiveness of intervention programs for perpetrators and victims of intimate partner violence," Partner Abuse, vol. 4, no. 2, pp. 196-231, 2013.

[18] W. W. Hudson and S. R. McIntosh, "The assessment of spouse abuse: two quantifiable dimensions," Journal of Marriage and the Family, vol. 43, no. 4, pp. 873-888, 1981.

[19] L. L. Marshall, "Development of the severity of violence against women scales," Journal of Family Violence, vol. 7, no. 2, pp. 103-121, 1992.

[20] P. A. Ortega-Ceballos, J. Mudgal, Y. Flores, L. Rivera-Rivera, J. C. Díaz-Montiel, and J. Salmerón, "Determinantes de violencia de pareja en trabajadoras del IMSS morelos," Salud Pública de México, vol. 49, no. 5, pp. 357-366, 2007.

[21] R. Axelrod, "Advancing the art of simulation in the social sciences," in Simulating Social Phenomena, pp. 21-40, Springer Berlin Heidelberg, Heidelberg, Germany, 1997.

[22] D. Mossman, "Assessing predictions of violence: being accurate about accuracy," Journal of Consulting and Clinical Psychology, vol. 62, no. 4, pp. 783-792, 1994.

[23] G. Bach-Y-Rita, J. R. Lion, C. E. Climent, and F. R. Ervin, "Episodic dyscontrol: a study of 130 violent patients," American Journal of Psychiatry, vol. 127, no. 11, pp. 1473-1478, 1971.

[24] R. Caetano, S. Ramisetty-Mikler, and C. A. Field, "Unidirectional and bidirectional intimate partner violence among white, black, and hispanic couples in the United States," Violence and Victims, vol. 20, no. 4, pp. 393-406, 2005.

[25] W. Y. Yang, W. Cao, T. S. Chung, and J. Morris, Applied Numerical Methods Using Matlab, John Wiley \& Sons, Hoboken, NJ, USA, 2005.
[26] E. J. MacKenzie, S. Shapiro, and J. N. Eastham, "The abbreviated injury Scale and injury severity score: levels of interand intrarater reliability," Medical Care, vol. 23, no. 6, pp. 823-835, 1985. 